\title{
Bodo Pieroth
}

Deutsche Schriftsteller als angehende Juristen

Juristische Zeitgeschichte

Abteilung 6, Band 51 


\section{Juristische Zeitgeschichte}

Hrsg. von Prof. Dr. Dr. Thomas Vormbaum

(FernUniversität in Hagen, Institut für Juristische Zeitgeschichte)

\section{Abteilung 6: \\ Recht in der Kunst - Kunst im Recht \\ Mithrsg. Prof. Dr. Gunter Reiß \\ (Universität Münster)}

Band 51

Redaktion: Anne Gipperich 
Bodo Pieroth

\section{Deutsche Schriftsteller als angehende Juristen}

De Gruyter 
Professor Dr. Bodo Pieroth, Jahrgang 1945, hat nach dem Jurastudium in München, Bonn und Freiburg, dem Erwerb eines Diploms in Nizza und der Referendarzeit in Baden-Württemberg bis zu seinem Eintritt in den Ruhestand 42 Jahre lang an Universitäten gelehrt: als Doktorand und Habilitand in Heidelberg, als Professor für Öffentliches Recht in Bochum, Marburg und Münster, wo er auch das Institut für Öffentliches Recht und Politik geleitet hat, sowie als Gastprofessor in Frankreich und den USA. Auf den Gebieten des Verfassungsrechts, der Verfassungsgeschichte, des Polizeirechts und des Kulturrechts sowie zum Thema Recht und Literatur hat er über 400 Publikationen vorgelegt. Für Literatur hat er sich sein Leben lang begeistert.

ISBN 978-3-11-061487-9

e-ISBN (PDF) 978-3-11-061733-7

e-ISBN (EPUB) 978-3-11-061494-7

Library of Congress Control Number: 2018951337

\section{Bibliografische Information der Deutschen Nationalbibliothek}

Die Deutsche Nationalbibliothek verzeichnet diese Publikation in der Deutschen Nationalbibliografie; detaillierte bibliografische Daten sind im Internet über http://dnb.dnb.de abrufbar.

(C) 2018 Walter de Gruyter GmbH, Berlin/Boston

Abbildung auf dem Schutzumschlag: akg-images / Franz Kafka: Zeichnung von Johann Brandstetter

Druck und Bindung: CPI books GmbH, Leck

www.degruyter.com 